\title{
A New Perspective on Alzheimer's Disease as a Brain Expression of a Complex Metabolic Disorder
}

\author{
Baruh Polis • Abraham O. Samson \\ Drug Discovery Laboratory, The Azrieli Faculty of Medicine, Bar-Ilan University, \\ Safed, Israel
}

Author for correspondence: Baruh Polis, The Azrieli Faculty of Medicine, Bar-Ilan University, 8th Henrietta Szold Street, P.O. Box 1589, Safed 1311502, Israel.

Email: baruhpolis@gmail.com

Doi: http://dx.doi.org/10.15586/alzheimersdisease.2019.ch1

\begin{abstract}
Alzheimer's disease (AD) is an irredeemable chronic neurodegenerative disorder and the predominant cause of dementia. The disease progression is associated with the deposition of amyloid plaques and formation of neurofibrillary tangles in the brain, yet clinical dementia is the end and culminating stage of the enduring pathology. Recent evidence suggests that $\mathrm{AD}$ is characterized by distinctive abnormalities apparent on systemic, histological, macromolecular, and biochemical levels. Besides the well-described characteristic profuse neurofibrillary tangles, dystrophic neurites, and $\mathrm{A} \beta$ deposits, the $\mathrm{AD}$ pathology includes substantial neuronal loss, inflammation, extensive DNA damage, considerable mitochondrial malfunction, impaired energy metabolism, and chronic oxidative stress. Moreover, severe metabolic dysfunction leading to oxidative stress is a possible cause and hallmark of $\mathrm{AD}$ that is apparent decades before the disease manifestation. State-of-the-art metabolomics studies have proved that arginine and branched-chain amino acids metabolism disturbances accompany AD and contribute to its pathogenesis. Repetitive failures to find an efficient anti-amyloid or anti-Tau treatment, which would face the challenges of the complex AD pathology, led to the hypothesis that hyperphosphorylated Tau and deposited
\end{abstract}

In: Alzheimer's Disease. Thomas Wisniewski (Editor), Codon Publications, Brisbane, Australia. ISBN: 978-0-646-80968-7; Doi: http://dx.doi.org/10.15586/alzheimersdisease.2019

Copyright: The Authors.

License: This open access article is licensed under Creative Commons Attribution 4.0 International (CC BY 4.0). https://creativecommons.org/licenses/by-nc/4.0/ 
$\mathrm{A} \beta$ proteins are hallmarks, not the ultimate causes of AD. Accordingly, the modern scientific vision of AD etiology and pathogenesis must reach beyond the hallmarks and look for alternative strategies and areas of research.

Keywords: Alzheimer's disease; arginase; arginine; branched-chain amino acids; oxidative stress; urea cycle

\section{INTRODUCTION}

Alzheimer's disease (AD) is a severe chronic neurodegenerative disorder and the leading cause of dementia (1). The gradual progression of cognitive decline is associated with characteristic brain atrophy, amyloid plaques deposition, and neurofibrillary tangles (NFT) formation (2). More than 100 years ago, AD has been described as an extremely rare pathology and, in fact, it was uncommon before the baby-boomers began to reach retirement age. Nowadays, it looks like one of the most significant medical, social, and economic challenges that faces the 21 st century. Growing life-expectancy, high sugar and fat diet, and sedentary lifestyle have led to an epidemic-like and exponential dissemination of the disease within various social and national strata. Today, more than 50 million individuals suffer from the stage of AD that we refer to as dementia worldwide, and this number is expected to triple by 2050 (3).

Despite a century-long rigorous investigation, there is no complete scientific consensus regarding the causes of $\mathrm{AD}$. The prevailing current view among scientists centers upon the amyloid cascade hypothesis $(4,5)$. However, growing clinical and empirical evidence points to extremely complex systemic pathophysiology accompanying AD-associated cognitive impairment and even contributing to its development decades prior to the clinical manifestation $(6,7)$.

The recent introduction of novel biomarkers for early detection and clinical management of $\mathrm{AD}$ has improved the diagnostic precision and qualification of neuropathology. The new techniques provide practical tools for more objective assessment of the treatment outcomes and early therapeutic strategy correction, with emphasis on the molecular mechanisms of the disease. Moreover, this systems-level approach identifies sex and age-specific differences and further advances the development of personalized medicine.

$\mathrm{AD}$ is an incredibly complex illness, which constitutes a combination of numerous interrelated pathological events that include neurovascular, inflammatory, bioenergetic, and systemic metabolic processes. In addition to the classic, distinctive hallmarks, the disease is characterized by systemic abnormalities and brain metabolic aberrations, which are evident at molecular and biochemical levels. Accordingly, the typical contemporary description of AD-related pathology includes neuroinflammation, activation of apoptosis, mitochondrial dysfunction, metabolic impairment, and chronic oxidative stress.

Notably, oxidative damage is considered to be the earliest event in $A D$ pathology. Reliable data demonstrate an inverse correlation between levels of oxidative damage and both beta-amyloid $(A \beta)$ deposition and duration of dementia (8). Moreover, the formation of intraneuronal NFT is associated 
with reduced oxidative damage as well, which further supports the view that the onset of oxidative damage is an early event in AD pathogenesis.

Causes of brain oxidative stress include brain hypoperfusion due to advanced atherosclerosis or endothelial dysfunction, traumatic brain injury (TBI), infections, autoimmune disorders, insulin resistance (IR), and other diseases leading to neuroinflammation. Of note, the very first AD patient autopsy disclosed substantial brain atrophy and apparent arteriosclerosis (9). Recent converging evidence suggests that chronic cerebral hypoperfusion follows progressive aging due to cerebral atherosclerosis and endothelial dysfunction (10). These two interrelated pathological processes lead to brain energy crisis and trigger the characteristic neurodegeneration (11) (Figure 1).

Initial studies with focal ischemic insults and chronic cerebral hypoperfusion in rats have shown increased amyloid precursor protein (APP) translation levels followed by local $A \beta$ deposition in the brain parenchyma (12). Furthermore, chronic vascular insufficiency induces cleavage of the APP into A $\beta$-sized fragments in a rodent model (13). The used model of chronic blood-vessel occlusion demonstrated progressive accumulation of $A \beta$ peptide in the aged rats. Of note,

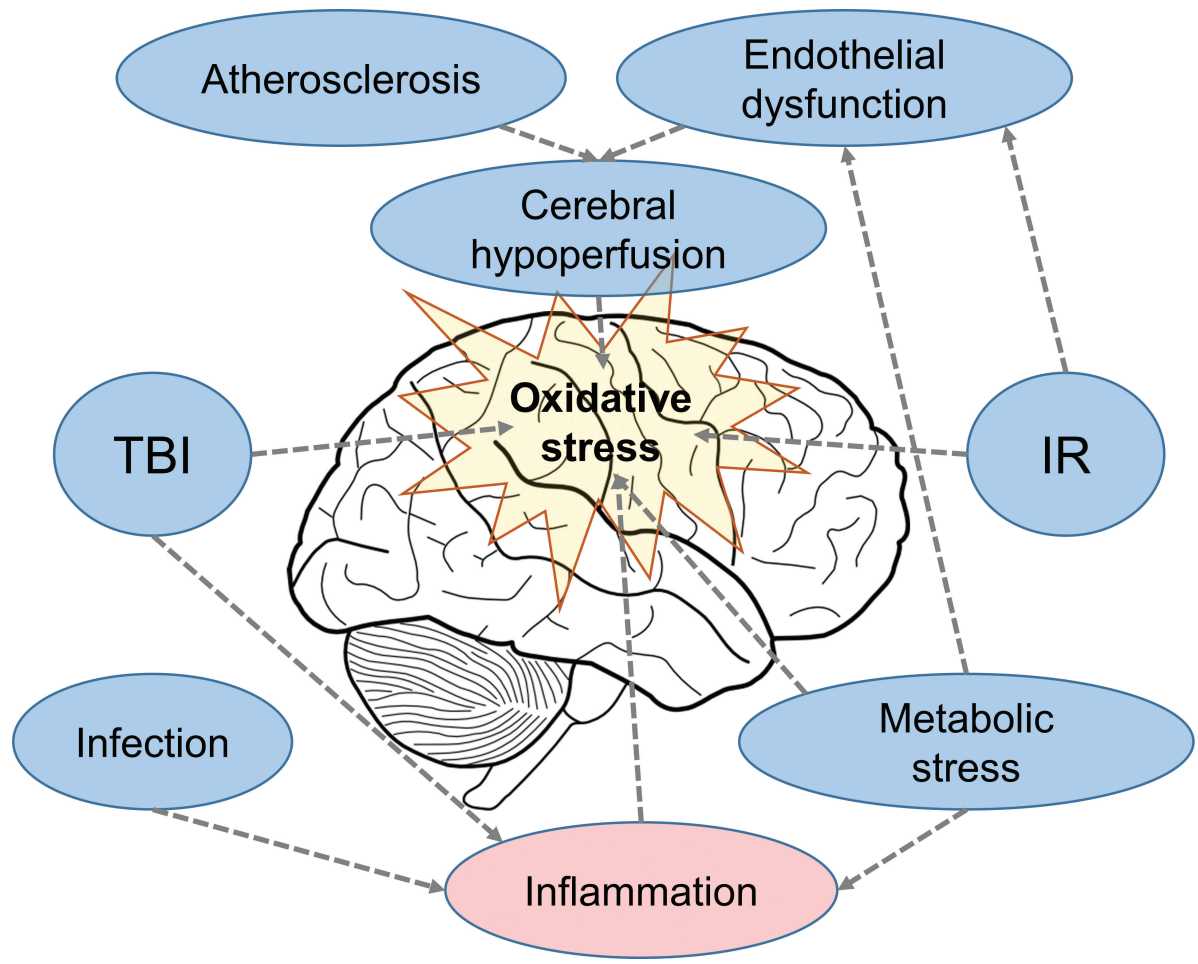

Figure 1 Main pathogenic factors of AD development. Cerebral hypoperfusion, metabolic stress, traumatic brain injury (TBI), and insulin resistance (IR) are the main causes of AD development. 
$A \beta$ deposition pattern displayed a gradual shift from neurons to the extracellular matrix, mimicking the characteristics of sporadic AD. The described hypoxiainduced response is attributed to a significant increase in the activities of APP amyloidogenic proteases ( $\beta$ - and $\gamma$-secretases), although nonamyloidogenic $\alpha$-secretase activity declines (14). Additionally, proinflammatory cytokines, and in particular tumor necrosis factor (TNF), prompt transcription of the APP gene via direct regulation of its promoter, which leads to overproduction and deposition of $\mathrm{A} \beta$ (15).

Brain tissue dreprivation of arginine has been suggested as a possible pathogenic mechanism leading to oxidative damage (16). Arginine deprivation leads to endothelial nitric oxide synthase (NOS3) substrate deficiency and enzymatic "uncoupling" due to induced arginase activation $(16,17)$. Uncoupling changes NOS3 enzymatic profile radically. As an alternative to oxidizing arginine to citrulline and NO, uncoupled enzyme reduces molecular oxygen to superoxide anion, which leads to neuronal oxidative stress (18).

Additionally, recent metabolomics studies have indicated characteristic branched-chain amino acids (BCAAs) deficiency as a metabolic signature of AD (19). BCAAs play an important role in glutamine/glutamate brain metabolism and provide nitrogen for at least one-third of the cerebral glutamate (20). Therefore, perturbations of BCAAs levels have a substantial impact on brain function and tip the scale between excitation and inhibition. Of note, BCAAs supplementation has been intensively investigated preclinically, demonstrating a therapeutic potential in different animal models of atherosclerosis (21), obesity (22), metabolic syndrome (23), and AD (24).

According to our model (Figure 2), AD is a spectrum of disorders, which has a mutual downstream pathway and pattern of manifestation with deviant biological reactions that eventually culminate in clinical dementia. We comprehend brain amyloidogenesis as a natural evolutionary conserved reaction to oxidative and metabolic stresses, which can be induced by numerous factors including nutrient imbalances. This view corresponds with the notion of $A \beta$ antioxidant functions in the aging and $\mathrm{AD}$ brain (27) and an influential concept, which deals with intraneuronal accumulation of $A \beta$, is a protective cellular mechanism to cope with oxidative insults (28). Moreover, amyloid aggregation and formation of extracellular amyloid plaques, where amyloid is in an insoluble form, are also an adaptive mechanism of the brain (29). This bioprocess reduces the concentration of the soluble toxic oligomeric and fibrillar species, which impair synaptic function and induce an inflammatory response. For that reason, there is a gradual reduction of $\mathrm{A} \beta$ concentration in the cerebrospinal fluid (CSF) of $\mathrm{AD}$ patients (30), the index that is inversely correlated with the cognitive decline (31).

\section{EARLY- AND LATE-ONSET AD ARE TWO DIFFERENT ENTITIES}

Advanced age is the main risk factor of AD (32). Nevertheless, its early onset is relatively common, representing about $5 \%$ of all cases (33). The very first case described by Alois Alzheimer was a woman who died at just 55 years from the disease. In fact, this case should be classified as an early-onset AD (EOAD) incident. This form is defined in the literature by clinical symptoms appearing 


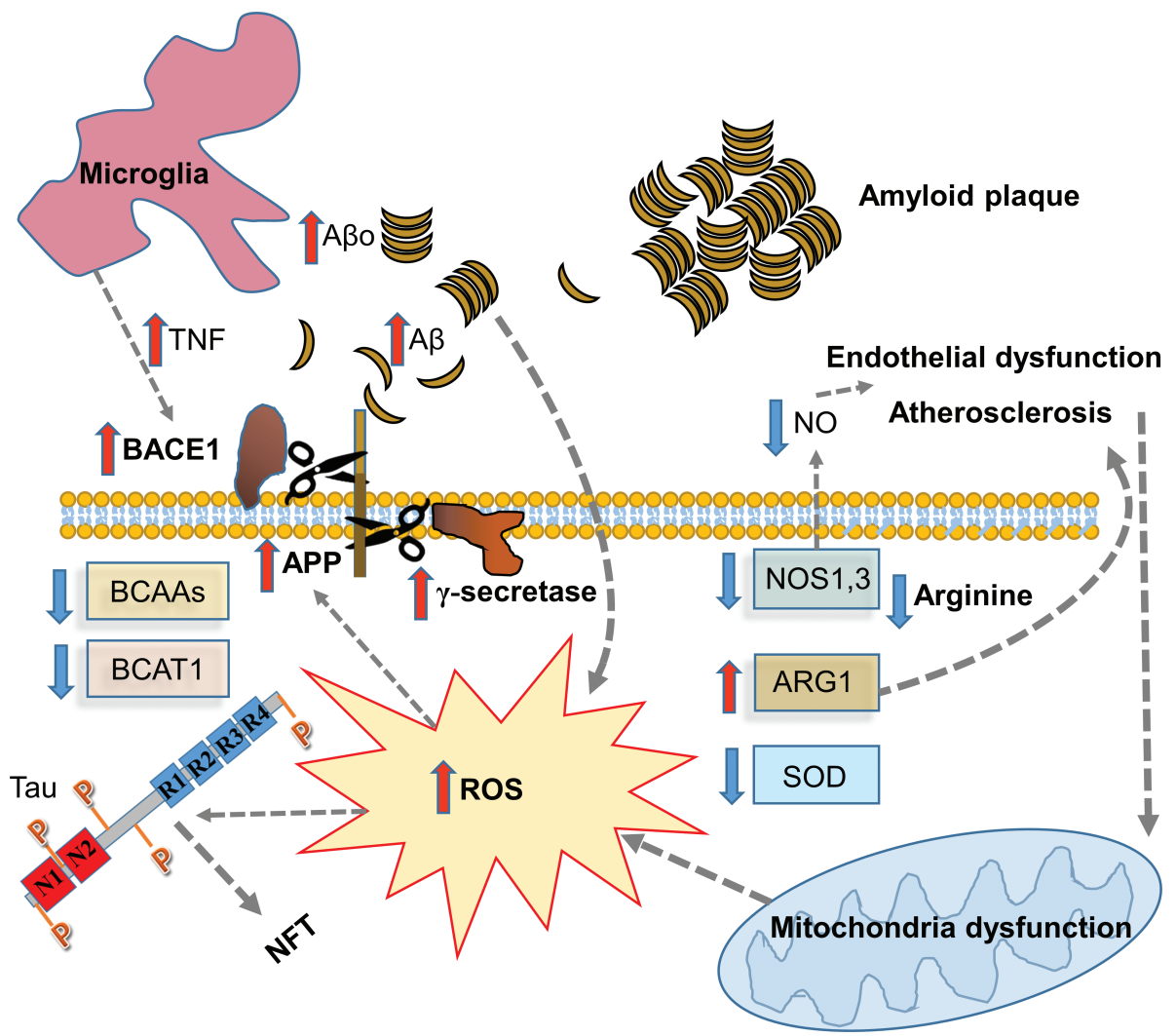

Figure 2 Proposed model of AD pathogenesis. The diagram presents oxidative stress induced by mitochondrial dysfunction, inflammation, or metabolic stress as the principal pathogenic AD event. Oxidative stress leads to an elevation in ROS levels and accumulation of oxidation products in neurons, which results in overexpression and increased processing of $A P P$ gene and eventually plaque formation (25), hyperphosphorylation of Tau and NFT pathology, which in turn produces more ROS and results in neurodegeneration and cellular death (26). $A \beta$ directly induces the production of ROS and further exacerbates oxidative stress and impairs endogenous antioxidant system including the activity of SODs.

before the age of 61 years (34). Generally, EOAD is inherited following dominant Mendelian fashion, although it represents a genetically heterogeneous group (35). Epidemiological data suggest that autosomal dominant familial AD (FAD) with PSEN1, PSEN2, and APP mutations accounts for about $0.5 \%$ of all AD cases (36); yet, the share of familial form in the group of EOAD rises to 13\% (34). Late-onset $\mathrm{AD}$ (LOAD) demonstrates a high heritability, with much more genes implicated in its development; however, the progression of LOAD is believed to be driven by a combination of genetic and environmental factors (37), and thus it remains to be principally idiopathic.

EOAD frequently manifests with distinguishable cognitive profile from LOAD. No evident amnesia characterizes the disease course, sometimes presenting just with language discrepancies, apraxia, and other uncommon functional 
deficits (38). Moreover, a specific memory impairment itself presents distinct patterns in EOAD and LOAD cases, with significantly more impaired semantic memory in LOAD than in EOAD patients (39). Recent objective data have demonstrated that EOAD CSF and fludeoxyglucose F $18\left({ }^{18} \mathrm{~F}-\mathrm{FDG}\right)$ positron emission tomography (PET) features substantially contrast with LOAD. CSF t-Tau shows significantly higher levels in EOAD patients (40). Moreover, ${ }^{18} \mathrm{~F}$-FDG PET scans of EOAD patients present the asymmetric patterns of hypometabolism with a localization that prominently differs from LOAD. Likewise, dementia severity in relatively young patients strongly correlates with amyloid plaques burden, but this direct relation progressively weakens with age and even disappears in the ninth decade of life (41). Of note, the term "dementia" itself is an umbrella term for cognitive impairment that interferes with one's ability to conduct routine daily affairs, and therefore extremely varies between different social groups.

Remarkably, at a molecular level, the $\mathrm{A} \beta$ oligomeric subtypes show a distinct pattern in each of $\mathrm{AD}$ forms. Amyloid pentameric species in the insoluble fraction are more abundant in EOAD than in LOAD (42). Additionally, elevated inflammatory markers, together with impaired renal function, distinguish LOAD, which points to substantial differences in pathogenesis and development between the two clinical forms of the disease (43).

These observations indicate that EOAD afflicting presenile populations represents a categorically separate pathological entity, which is characterized by distinctive pathophysiological mechanisms accountable for its unambiguous genetic background and uncommon clinical manifestation. In our opinion, only this form presents classic AD or presenile dementia of Alzheimer type.

In opposition to presenile form, the etiology of LOAD disease is much more heterogeneous, with a combined contribution of numerous genetic, age-related, and environmental factors. Unlike EOAD, LOAD often presents in comorbidity with diabetes and hypertension (44). Of note, no two patients have the same combination of the disease-related factors; therefore, the clinical appearance and the treatment strategies for this form have to be accurately personalized. Moreover, despite the apparent differences between presenile and senile forms of $\mathrm{AD}$, taxonomically they are still the same illness. In our opinion, LOAD is a syndrome, but not a stand-alone disease. It is a concurrence of correlated with each other convergent symptoms, and concurrence literally means syndrome (45). Thus, we suggest that the presence of the same confluent hallmarks, which characterize the EOAD and LOAD, does not reflect their mutual etiology and pathogenesis; therefore, attempts to link these two forms of $\mathrm{AD}$ to a single common causative agent are futile. For that reason, this chapter deals only with more common LOAD, which has a distinct metabolic signature.

\section{LOAD AS A SYSTEMIC METABOLIC DISORDER}

Converging evidence points to severe metabolic dysfunction as a leading cause and hallmark of AD (46). State-of-the-art metabolomics and imaging studies dealing with the immense complexity of the $\mathrm{AD}$ phenotype have disclosed this aspect of the disease. Gradual decline in cerebral metabolic rate is one of the earliest indicators that distinguish patients with mild cognitive impairment (MCI) and 
poses the clinical suspicion of prodromal AD (47), which suggests a key role of metabolic dysfunction in initial mechanisms of $\mathrm{AD}$ development. Likewise, advanced analyses of the brain tissue could detect explicit metabolic perturbations associated with $\mathrm{AD}$, both in humans (48) and mice (49).

A recent human postmortem unbiased lipidomics and metabolomics study has disclosed 34 metabolites, which distinguish frontal cortices' composition of AD patients from healthy controls (50). The authors identified six biochemical pathways, which are significantly altered in AD brains. The list of the pathways by their significance rate includes alanine, aspartate, and glutamate metabolism; arginine and proline metabolism; cysteine and methionine metabolism; glycine, serine, and threonine metabolism; purine metabolism; and pantothenate and CoA biosynthesis (50).

Metabolomics profiling of human plasma, which combines high-resolution mass spectrometry and advanced chemometrics and pathway enrichment analysis, indicates differentially affected polyamine and arginine metabolism in MCI subjects converting to AD (51).

Animal studies support and advance these findings. Multivariate statistical analysis of metabolite profiles of the brain, liver, and kidney tissues from APP/PS1 and wild-type (WT) mice indicates systemic nature of AD-associated pathophysiology (52). Liver and kidney samples from 6-month-old mice were fingerprinted using a high-throughput multi-platform metabolomics approach based on gas chromatography/mass spectrometry and reversed-phase liquid chromatography. Several observations pointed to the systemic character of the disorder with severely impaired glucose metabolism, mitochondrial dysfunction, and abnormal metabolism of BCAAs (52). Another longitudinal research performed in APP/PS1 transgenic and wild-type mice $(6,8,10,12$, and 18 months of age) with deep profiling of the brain and plasma metabolome proved severely disturbed polyamines and BCAAs metabolism (53).

Growing clinical evidence points to a widespread AD-related systemic disorder characterized by severely affected peripheral parenchymal organs and blood in similar magnitude as the brain (54). Remarkably, the scope and features of AD-associated metabolic abnormalities resemble advanced pathology observed in obese and diabetic patients (55). These common aberrations led to the hypothesis that $\mathrm{AD}$ represents a unique form of diabetes. A novel term "type 3 diabetes" has been coined and accepted in the scientific literature (56). This term reflects a substantial overlap at molecular and biochemical levels between $\mathrm{AD}$ and diabetes mellitus type 2 (57). Diabetic elderly patients were shown to develop extensive vascular abnormalities, which are associated with classic AD pathology (58). Likewise, recent data evidently and causatively relate obesity and AD (59).

Remarkably, several common treatment strategies for the abovementioned metabolic diseases are extremely effective, which proves mutual pathophysiology. Various preclinical and clinical studies have verified that a long list of drugs that are conventional in the treatment of diabetes, atherosclerosis, and other metabolic disorders improves the overall status, behavioral and cellular functions of AD patients. For instance, insulin-based therapy has emerged as a promising approach to halt AD-associated cognitive decline (60). Wang et al. evidenced a substantial effect of metformin upon neurogenesis and spatial memory acquisition in mice (61). A significant neuroprotective effect of metformin was demonstrated in rodents on a high-fat diet (HFD) (62). A recent meta-analysis study has proved 
that metformin use is associated with reduced risk of dementia in patients with diabetes (63). In order to evaluate the potentials of the drug as a disease-modifying medicine in $\mathrm{AD}$, a randomized 2-month-long placebo-controlled crossover study was performed, verifying the metformin-associated improvement in executive functioning (64).

Additionally, animal and human studies with thiazolidinediones have shown the potential to treat $\mathrm{AD}$ and diabetes. The treatment improves memory via facilitation of synaptic transmission and reduction of neurodegeneration $(65,66)$. Likewise, a broad variety of antioxidants are shown to be promising in atherosclerosis, $\mathrm{AD}$ (67), and diabetes mellitus (68). It is worth mentioning that chronic curcumin treatment improves the function of insulin-producing $\beta$-cells, reduces $A \beta$-associated cytotoxicity, mitigates Tau protein hyperphosphorylation, and alleviates neurodegeneration $(69,70)$.

Curiously, despite the lack of consensus about the AD etiology and pathogenesis, and absence of disease-modifying therapy, the disease prevalence in the western world has declined gradually over the last two decades (71). Several population-based studies have suggested that despite the growing absolute number of elderly people with dementia, age-specific risk of dementia is declining (72). In the USA alone, the proportion of elderly people with dementia has decreased by about 24\% between 2000 and 2012 (73). A similar trend was observed in England between 1991 and 2011 (74).

One possible explanation for the phenomenon might be recent considerable achievements in treatments of cardiovascular diseases and diabetes. The innovative widespread prevention and treatment strategies for these disorders include intensive medication with novel effective medicines. Therefore, the progress in the control of main dementia risk factors substantially assisted in reducing the prevalence of dementia among the target age groups.

Recent evidence suggests that AD-associated cognitive impairment is the outcome of extremely complex pathophysiology. In the light of new findings, more thorough consideration of the complexity of $\mathrm{AD}$ as a syndrome is required. Moreover, strategies targeting $\beta$-amyloid or Tau protein are not adequate to cure the disease; therefore, attempts to treat single hallmarks of $\mathrm{AD}$, such as plaques and tangles, are futile.

\section{A CONTRIBUTION OF THE UREA CYCLE AND POLYAMINE METABOLIC PATHWAY IN THE DEVELOPMENT OF AD}

The human brain weighs just $2 \%$ of the entire body weight but consumes about a fifth of the total glucose-derived energy, and consequently is highly vulnerable to oxidative stress (75). Neurons particularly are strongly dependent upon oxidative phosphorylation as an energy source, compared to other cells. As a general rule, oxidative stress increases with aging (76), which is followed by escalation of protein oxidation and extensive lipid peroxidation in susceptible organs and, particularly, in the brain. In the course of the progression of agerelated or AD-related neurodegeneration, neurons gradually lose their capacity of maintaining an appropriate redox balance. This imbalance leads to progressive accumulation of reactive oxygen species (ROS), mitochondrial dysfunction, and, 
eventually, to neuronal injury (77). Moreover, $A \beta$ deposits are directly associated with the free-radical generation, forming a vicious circle of AD pathogenesis $(78,79)$ (Figure 2).

Antioxidants are capable of transferring electrons to and from oxidizing agents, inhibiting free radicals production and reducing potential cell damages (80). Generally, antioxidants are classified into enzymatic agents (superoxide dismutase [SOD], catalase, glutathione peroxidase, glutathione reductase, etc.) and non-enzymatic agents (coenzyme Q10, carotenoids, vitamins E and C, and arginine) (81).

Arginine is a potent free radical scavenger (82) and protects neurons against oxidative stress through its antioxidant potentials (83). Its cationic nature contributes to the unique protonative properties and ability to react directly with the superoxide anion radical (84). Thus, arginine and its derivatives regulate membrane peroxidation processes (85). Although the human cells are capable of synthesizing arginine, its external supplementation is necessary for infants and the elderly, making arginine conditionally essential (86). Moreover, some clinical conditions lead to depletion of endogenous arginine resources, which escalates the demand for it. Among these conditions are severe infections, burns, wounds, intensive physical activity, and sterility (87).

Several recent studies have explored the association between age-related cognitive function decline and aberrations in brain arginine metabolism. An animal study has disclosed altered arginine metabolic profile even prior to any memory deficit (88), which proves the parallel development of brain arginine metabolism aberrations and behavioral deficits in AD mice. Moreover, behavioral deficits and brain profile alternations follow the changes in plasma arginine metabolic profile, which advocates the use of arginine-centric antemortem biomarkers for the early diagnosis of $\mathrm{AD}$ (88). More recent data from the same laboratory have demonstrated a significantly altered brain arginine metabolism in a mouse model of tauopathy (89). Noticeable changes were observed in ornithine, polyamines, and glutamate concentrations, which further suggest a shift of arginine metabolism to the direction of arginase-polyamine pathway in $\mathrm{AD}$ rodent models brain.

Additional evidence indicates severe arginine metabolism disturbances in various brain areas and points to significantly escalated arginase activity in the hippocampi of AD patients (90). Another study has reported decreased levels of arginine in the cortices of AD patients (91). Moreover, innovative capillary electrophoresis-mass spectrometry metabolomics investigations of AD patients' CSF detect a decline in arginine levels $(92,93)$. Remarkably, urine levels of arginine in amnestic MCI patients are also significantly lower than in normal controls (94). Additionally, these patients demonstrate a reduced global arginine bioavailability ratio, the index, which is positively correlated with the Mini-Mental Status Examination score, making urinary arginine levels a potential diagnostic biomarker for MCI. Of note, numerous animal studies have further implicated altered arginine metabolism in the pathogenesis of $\operatorname{AD}(95,96)$.

Arginine was shown to mitigate hydrogen peroxide-induced apoptosis and protect against $A \beta_{(25-35)}$-induced toxicity in cultured PC-12 cells (97). The amino acid supplementation improves cognitive function in demented elderly (98). Additionally, its administration within 30 min of a stroke significantly decreases the frequency and severity of symptoms (99). 
Arginine overcomes biological barriers via ubiquitously expressed high-affinity permeases or cationic amino acid transporters (CATs), which are involved in the transport of the cationic amino acids (arginine, lysine, histidine, etc.) (100). Arginine is generally transported from the circulating blood into the brain via CAT1, which is excessively expressed at the blood-brain barrier (BBB) $(101,102)$. The amino acid influx transport in the rat model has been proven to be saturable with a Michaelis-Menten constant (Km) value of $56 \mu \mathrm{M}$. Of note, the physiological serum concentration of arginine is about $170 \mu \mathrm{M}$ in rodents and about $100 \mu \mathrm{M}$ in men (103). Consequently, the capacity of its transport system is substantially limited (104) that makes traditional arginine supplement insufficient to demonstrate all of its possible effects. Therefore, the pharmacological targeting of enzymes that metabolize arginine in order to improve its availability is a likely beneficial method to treat neurological conditions (17).

Arginase cleaves arginine to produce urea and ornithine at the last step of the urea cycle, which generally protects the cells against ammonia toxicity, while ornithine and its downstream derivatives participate in collagen formation, induce cell proliferation, and influence other vital physiological processes (Figure 3). A substantial increase in arginase activity contributes to vascular dysfunction in the atherosclerotic (apolipoprotein E deficient) mice by interfering in the function of the neurovascular unit, which leads to BBB leakage and neuroinflammation (105).

Arginine is the immediate precursor of $\mathrm{NO}$ and other bioactive molecules (Figure 3). Nitric oxide synthases (NOSs) utilize arginine as a substrate to produce NO and citrulline (106). Consequently, the bioavailability of arginine is a regulating factor for NO synthesis (107). Arginine-derived NO serves as a potent antioxidant agent protecting cells from damage caused by ROS (108). It causes vasodilation and improves blood supply to neurons, which reduce their susceptibility to oxidative stress (109). Likewise, NO moderates $\mathrm{Ca}^{2+}$ influx into the neurons, protecting them from excitotoxicity (110). Remarkably, under physiological conditions, the molecule represents a key endothelium protective factor (111) but becomes detrimental under oxidative stress. Substrate deficiency leads to NOS3 uncoupling and deviation from NO synthesis, converting it to a superoxideproducing enzyme (112). A significant reduction of NOS activity in AD brains, with a decrease in the levels of NOS1 and NOS3 proteins, has been reported (90). Moreover, $\mathrm{AD}$-associated arginase overactivation substantially limits mutual substrate availability, and is followed by a decrease in NO production (113). This mechanism is particularly important in the statuses with limited extracellular resources of arginine, like advanced age, for example.

The arginase expression is induced by various stimuli, including cytokines, catecholamines, lipopolysaccharide, TNF, oxidized low-density lipoprotein, and hypoxia $(114,115)$. In the brains of the AD model mice, arginase 1 (Argl) was shown to be not only localized in the cells but also distributed in the extracellular space. In the hippocampus, it displays a spatial correlation with $A \beta$ deposition, and Ibal expression (16). In addition, activation of arginase 2 (Arg2) is associated with translocation from the mitochondria to the cytosol $(116,117)$ (Figure 3).

Recent evidence points to escalated Arg2 gene expression in AD brains (118). Moreover, Arg2 deficiency reduces the rate of hyperoxia-mediated retinal neurodegeneration (119), suggesting the contribution of arginase in the neuronal 


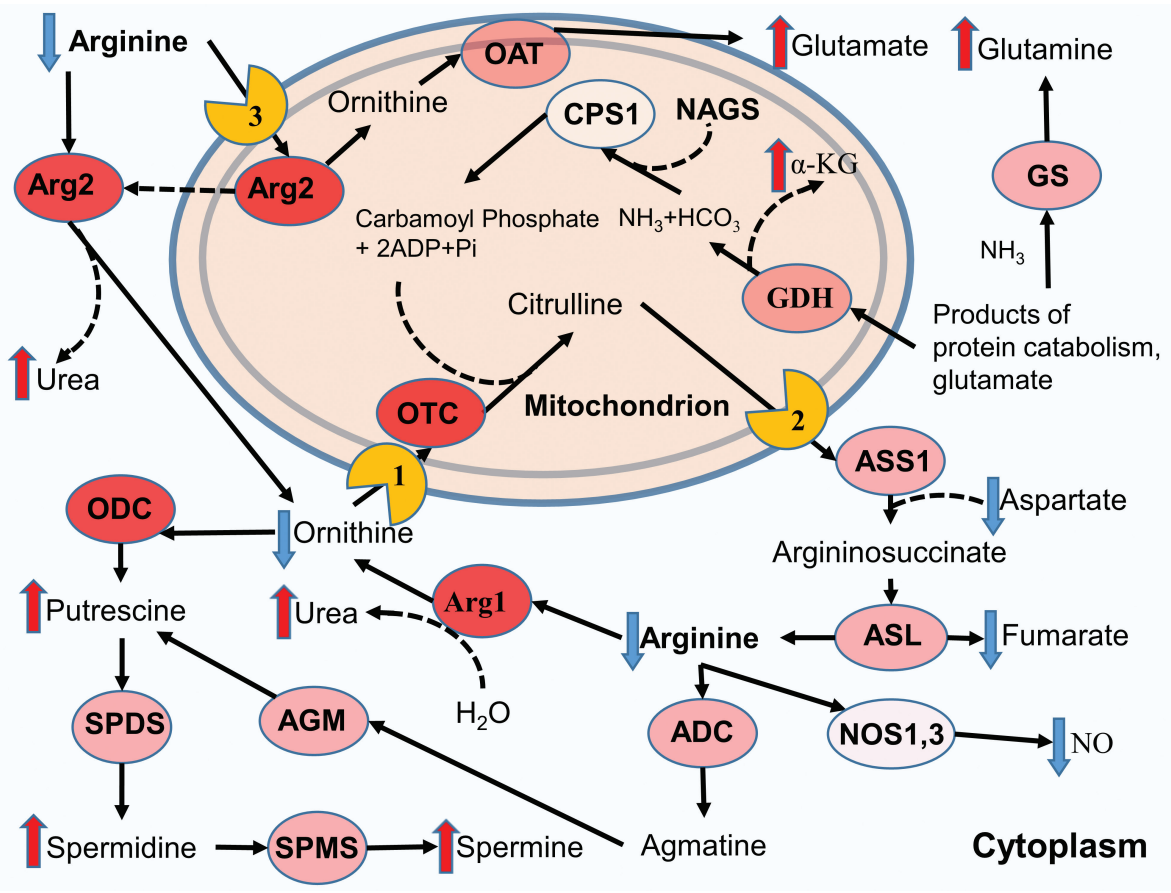

Figure 3 Arginine metabolic pathways and their deviations in AD brain. Arginine is primary substrate metabolized by nitric oxide synthases (NOS1 and NOS3 under physiological conditions), arginase 1 (Arg1) and arginine decarboxylase (ADC). Arginase 2 (Arg2) plays a role in extra-urea cycle arginine metabolism. Arginine is cleaved by arginase to form urea and ornithine at the final step of the urea cycle. The urea cycle consists of $\mathrm{N}$-acetylglutamate synthase (NAGS), which is an allosteric cofactor for catalytic enzyme carbamoyl phosphate synthase (CPS1), and other four catalytic enzymes: ornithine transcarbamylase (OTC), argininosuccinate synthetase (ASS1), argininosuccinate lyase (ASL), and arginase 1 (Arg1). NAGS, CPS1 and OTC are localized in the mitochondria, while ASS1, ASL, and ARG1 are in the cytosol. Two enzymes: OTC and CPS1 are present in very low concentrations in the human brain. As a result, the brain urea cycle is not efficient and to remove ammonia and relies on alternative glutamine synthesis by glutamine synthetase (GS). Glutamine concentration rises in AD brain. Glutamate dehydrogenase (GDH) catalyzes the deamination of glutamate to $\alpha$-ketoglutarate $(\alpha-K G)$, which concentrations also increase in AD brain, and ammonia (NH3). The mitochondrial ornithine transporter (1), citrin (2), and the mitochondrial cationic amino acid transporter type 1 (3). Red arrows indicate elevated levels; blue arrows designate reduced ones. The intensity of the circles' color reflects the level of activation (arbitrary scale). Argininosuccinate lyase (ASL), argininosuccinate synthetase (ASS), nitric oxide (NO), ornithine decarboxylase (ODC), spermidine synthase (SPDS), spermine synthase (SPMS), agmatinase (AGM), ornithine aminotransferase (OAT).

degeneration via overactivation of the N-methyl-D-aspartate receptors (120). Accordingly, targeting Arg2 has been proposed as a means of decelerating age-related diseases treatment (121).

Inhibition of ornithine decarboxylase (ODC) with $\alpha$-difluoromethylornithine has been proved to be neuroprotective in a rodent model of AD (16). The authors speculated that arginine deprivation is a critical AD pathogenic factor, which eventually leads to neuronal death and cognitive deficits. We have hypothesized 
that upregulation of arginase activity and consequent arginine and NO deficiency, in the brain areas characterized by excessive amyloid deposition, contribute to the clinical manifestation of AD (17). Accordingly, we targeted arginase, but not ODC, with its uncompetitive inhibitor, norvaline, to ameliorate the symptoms of the disease (117).

Norvaline has been proven to be a potent inhibitor of urea synthesis in isolated rat liver cells (122). It also inhibits arginase in vivo via negative feedback inhibition mechanism due to its structural similarity with ornithine (123). Moreover, the inhibition process is enantiomer dependent because its stereoisomer, D-norvaline, does not affect NO production (113). The potency of norvaline to amplify the rate of $\mathrm{NO}$ production has been evidenced in vitro (113). In addition, the substance was effectively used in a rat model of artificial metabolic syndrome (23).

Remarkably, norvaline also effectively inhibits ornithine transcarbamylase (OTC) activity, the mitochondrial enzyme converting ornithine to citrulline (124) (Figure 3). OTC is extensively expressed in AD brains, but not in controls, which is followed by about ninefold increase in OTC activity in the CSF (125). Epidemiological studies have revealed that single nucleotide polymorphism of the OTC gene promoter is associated with $\mathrm{AD}$ morbidity, suggesting that the OTC gene is a minor genetic AD determinant (126). OTC activation leads to apparent ornithine deficiency (90) and, in turn, arginase activation via product inhibition insufficiency. Thus, the vicious circle of metabolic changes acts in the $\mathrm{AD}$ brain (Figure 3). Accordingly, norvaline is capable of correcting the AD-related arginine metabolism aberrations by inhibiting two central enzymes of the urea cycle.

\section{A PUTATIVE ROLE OF BCCAS IN THE DEVELOPMENT OF AD}

BCAAs are the amino acids possessing branched aliphatic side-chains. There are three proteinogenic BCAAs-valine, leucine, and isoleucine, which are essential amino acids - and several non-proteinogenic BCAAs, including 2-aminoisobutyric acid and 2-aminopentanoic acid (norvaline) (127). It is worth mentioning that the vast majority of essential amino acids are metabolized in the liver; however, BCAAs escape the first-pass hepatic catabolism and are mainly oxidized in skeletal muscles, adipose tissue, and the brain (128).

BCAAs catabolism initiates with a transamination reaction catalyzed by the branched-chain aminotransferases (BCATs). The family of BCATs consists of two isoforms: mitochondrial BCAT2 and cytosolic BCAT1. BCATs are mutual to all three BCAAs, and transamination by BCATs is the exclusive reaction for BCAAs only. The products of the reaction are glutamate and three different branchedchain $\alpha$-ketoacids (BCKAs). Of note, other non-proteinogenic BCAAs (for instance, norvaline) are competent to be substrates for BCAT in rodents and humans (129).

There are indications that BCAAs play a different role in the brain compared to other tissues. BCAT1 and BCAT2 are expressed prominently in the brain cells, where the enzymes maintain the continuous supply of the principal excitatory neurotransmitter glutamate. Remarkably, BCAT1 is present predominantly in neurons, while the appearance of BCAT2 is limited to astrocytes $(130,131)$. 
In the mammalian brain, BCAAs are involved in several vital processes. Among them are key neurotransmitters' metabolism, protein synthesis, and energy production (132). Glutamate is the principal excitatory neurotransmitter of the mammalian brain (133), and its concentrations are substantially higher in brain than in plasma (134). Glutamate does not cross the BBB in considerable quantities, except in regions with fenestrated capillaries (135); therefore, neuronal glutamate has to be continually synthesized from constantly accessible and reliable precursors. Its synthesis requires an efficient amino group donor, which is transported rapidly into the brain and is readily transaminated. BCAAs meet these needs optimally. Their unique properties and availability allow them to play a central role in glutamate metabolism. It was estimated that at least one-third of the cerebral glutamate contains nitrogen derived from the BCAAs (20). Consequently, perturbations in the levels of BCAAs meaningfully influence the whole function of the central nervous system, and the balance of excitation and inhibition, in particular.

González-Domínguez et al. utilized gas chromatography coupled with mass spectrometry to profile low-molecular-weight metabolites in serum of newly diagnosed sporadic AD patients who had not received any medication yet (136). Alterations of 23 metabolites were detected, including significantly decreased valine levels. In a more recent study including hundreds of participants conducted by Toledo et al., lower plasma valine levels were shown to correlate with the rate of cognitive decline. Likewise, the coefficient for valine was negatively associated with actual ventricular volume changes. Accordingly, an increase in valine concentration was associated with a significantly decreased risk of AD (137). Another study by Tynkkynen et al. utilized innovative profiling of blood metabolites via nuclear magnetic resonance and mass spectrometry (19). Remarkably, lower levels of all three BCAAs were strongly associated with an increased risk of dementia and $\mathrm{AD}$ in a combined meta-analysis with a replication sample.

In our original studies in a rodent model of $\mathrm{AD}$, we provided the mice with arginase inhibitor non-proteinogenic BCAA norvaline, which is an isoform of valine (117). The animals treated with norvaline demonstrated significantly improved spatial memory acquisition, associated with an increase in hippocampal spine density, and reduced neuroinflammation. Moreover, the rate of the brain amyloidosis was significantly diminished due to a reduction in the expression levels of the APP, which was followed by a significant increase in [Cu-Zn] superoxide dismutase levels, suggesting improvement of the internal antioxidant mechanisms (24). Further investigations will shed light on the potential of BCAAs to halt $\mathrm{AD}$ progression.

\section{CONCLUSION}

Scientific society has already sought a potent AD-modifying medication for more than a century. Unfortunately, its best efforts have been to no avail. A cornucopia of agents has been trialed, hoping to preclude the impending calamity, but with no conclusive results. The primary cause of the continual failures is the misleading and highly controversial hypothesis, which besets the development of adequate $\mathrm{AD}$ therapy. 
The chronic absence of an AD-modifying drug, despite multibillion dollar research and development investment, puzzles the best scientific minds and enigmatizes the entire field of knowledge. Continual failure to rise to the challenges of the multifaceted AD pathology and offer an efficient diseasemodifying therapy predicated upon the dominant during the last 30 years amyloid cascade hypothesis, with aggressive anti-amyloid or anti-Tau treatments, led to the suggestion that hyperphosphorylated Tau and deposited A $\beta$ proteins are just hallmarks and not the ultimate causes of $\operatorname{AD}(139,140)$. Accordingly, treatment strategies targeting beta-amyloid or Tau protein are not competent to cure the disease (140). As a result, a novel trend in academic research and preclinical drug development is directed toward the discovery of therapeutic agents targeting altered brain metabolism and energetics (141). Recently proposed novel strategies based on a universal approach to the problem of $\mathrm{AD}$ and a progressive vision of the disease etiology and pathogenesis reaching beyond the conventional hallmarks provide a hope to halt the looming epidemic.

Current metabolomics techniques are based on a comprehensive understanding of AD pathophysiology, which is predicated upon the detailed knowledge of its peculiarities, the disease onset coincidences, and the precise order of the pathology development. In this context, an emerging metabolic hypothesis of $\mathrm{AD}$, which is strongly supported by empirical evidence, and treats the classic hallmarks of the disease as the epiphenomena of the major complex pathology, has promising potential to offer a competent therapeutic solution.

Moreover, this new concept proposes a novel approach to the clinical classification and the treatment strategy for two distinct forms of AD. There is a consensus about the considerable differences between EOAD and LOAD. These two forms of AD have dissimilar courses, different genetic backgrounds and clinical manifestations, and are followed by unrelated metabolic impairments. Therefore, they have to be treated as separate entities.

In categorizing LOAD as a brain expression of a systemic complex metabolic disorder, which shares similarities and pathogenic pathways with diabetes mellitus, obesity, and atherosclerosis, we suggest common treatment and preventive strategies for all these pathologies. Therefore, regular physical and mental activity, diet, blood glucose, cholesterol levels monitoring and regulation, and antioxidants supplementation have particular importance in $\mathrm{AD}$ prevention and treatment. Moreover, novel emerging potent medicines, which have been successfully trialed in patients with various systemic metabolic diseases, might be extremely effective in $\mathrm{AD}$ patients as well.

We suggest that inclusive $\mathrm{AD}$ treatment strategies, targeting both brain and systemic abnormalities, are more effective than strategies that target CNS abnormalities alone. Such approaches should include an auxiliary intervention into the metabolic pathways and personalized correction of misbalances. Likewise, the systemic management of AD comorbidities and mutual risk factors is a central part of preventive $\mathrm{AD}$ therapy.

In addition, we argue that, in the case of LOAD, early prevention is the best healthcare salutary strategy. Consequently, the most critical current objectives are the empowerment of people with the ability to change their lifestyle, and the arming of doctors with the appropriate tools and medicines to halt the $\mathrm{AD}$ development. 
Conflict of interest: The authors declare no potential conflicts of interest with respect to research, authorship, and/or publication of this chapter.

Copyright and Permission Statement: To the best of our knowledge, the materials included in this chapter do not violate copyright laws. All original sources have been appropriately acknowledged and/or referenced. Where relevant, appropriate permissions have been obtained from the original copyright holder(s).

\section{REFERENCES}

1. Alzheimer's Association. 2016 Alzheimer's disease facts and figures. Alzheimers Dement. 2016;12(4):1-80.

2. Goedert M, Spillantini MG. A century of Alzheimer's disease. Science. 2006;314(5800):777-81. http://dx.doi.org/10.1126/science.1132814

3. Christina P. World Alzheimer report 2018. The state of the art of dementia research: New frontiers. London: Alzheimer's Disease International (ADI); 2018.

4. Hardy J, Allsop D. Amyloid deposition as the central event in the aetiology of Alzheimer's disease. Trends Pharmacol Sci. 1991;12(10):383-8. http://dx.doi.org/10.1016/0165-6147(91)90609-V

5. Hardy JA, Higgins GA. Alzheimer's disease: The amyloid cascade hypothesis. Science. 1992;256(5054):184-5. http://dx.doi.org/10.1126/science.1566067

6. Sonntag KC, Ryu WI, Amirault KM, Healy RA, Siegel AJ, McPhie DL, et al. Late-onset Alzheimer's disease is associated with inherent changes in bioenergetics profiles. Sci Rep. 2017;7(1):14038. http:// dx.doi.org/10.1038/s41598-017-14420-x

7. Wilkins JM, Trushina E. Application of metabolomics in Alzheimer's disease. Front Neurol. 2018;8:719. http://dx.doi.org/10.3389/fneur.2017.00719

8. Nunomura A, Perry G, Aliev G, Hirai K, Takeda A, Balraj EK, et al. Oxidative damage is the earliest event in Alzheimer disease. J Neuropathol Exp Neurol. 2001; 60(8):759-67. http://dx.doi. org/10.1093/jnen/60.8.759

9. Pearce JMS. Alzheimer's disease. J Neurol Neurosurg Psychiatry. 2000;68:348. http://dx.doi. org/10.1136/jnnp.68.3.348

10. De La Torre JC. Cerebral hemodynamics and vascular risk factors: Setting the stage for Alzheimer's disease. J Alzheimers Dis. 2012;32(3):553-67. http://dx.doi.org/10.3233/JAD-2012-120793

11. De La Torre JC. Pathophysiology of neuronal energy crisis in Alzheimer's disease. Neurodegener Dis. 2008;5(3-4):126-32. http://dx.doi.org/10.1159/000113681

12. Kalaria RN, Bhatti SU, Lust WD, Perry G. The amyloid precursor protein in ischemic brain injury and chronic hypoperfusion. Ann N Y Acad Sci. 1993;695:190-3. http://dx.doi. org/10.1111/j.1749-6632.1993.tb23050.x

13. Bennett SAL, Pappas BA, Stevens WD, Davidson CM, Fortin T, Chen J. Cleavage of amyloid precursor protein elicited by chronic cerebral hypoperfusion. Neurobiol Aging. 2000;21(2):207-14. http:// dx.doi.org/10.1016/S0197-4580(00)00131-7

14. Salminen A, Kauppinen A, Kaarniranta K. Hypoxia/ischemia activate processing of amyloid precursor protein: Impact of vascular dysfunction in the pathogenesis of Alzheimer's disease. J Neurochem. 2017;140(4):536-49. http://dx.doi.org/10.1111/jnc.13932

15. Lahiri DK, Chen D, Vivien D, Ge YW, Greig NH, Rogers JT. Role of cytokines in the gene expression of amyloid $\beta$-protein precursor: Identification of a 5'-UTR-binding nuclear factor and its implications in Alzheimer's disease. J Alzheimers Dis. 2003;5(2):81-90. http://dx.doi.org/10.3233/JAD-2003-5203

16. Kan MJ, Lee JE, Wilson JG, Everhart AL, Brown CM, Hoofnagle AN, et al. Arginine deprivation and immune suppression in a mouse model of Alzheimer's disease. J Neurosci. 2015;35(15):5969-82. http://dx.doi.org/10.1523/JNEUROSCI.4668-14.2015

17. Polis B, Samson AO. Arginase as a potential target in the treatment of Alzheimer's disease. Adv Alzheimers Dis. 2018;7:119-40. http://dx.doi.org/10.4236/aad.2018.74009 
18. Loscalzo J. An experiment of nature: Genetic L-arginine deficiency and NO insufficiency. J Clin Investig. 2001;108(5):663-4. http://dx.doi.org/10.1172/JCI13848

19. Tynkkynen J, Chouraki V, van der Lee SJ, Hernesniemi J, Yang Q, Li S, et al. Association of branchedchain amino acids and other circulating metabolites with risk of incident dementia and Alzheimer's disease: A prospective study in eight cohorts. Alzheimers Dement. 2018;14(6):723-3. http://dx.doi. org/10.1016/j.jalz.2018.01.003

20. Yudkoff M. Brain metabolism of branched-chain amino acids. Glia. 1997;21(1):92-8. http://dx.doi. org/10.1002/(SICI)1098-1136(199709)21:1\%3C92::AID-GLIA10\%3E3.0.CO;2-W

21. Zhao Y, Dai XY, Zhou Z, Zhao GX, Wang X, Xu MJ. Leucine supplementation via drinking water reduces atherosclerotic lesions in apoE null mice. Acta Pharmacol Sin. 2016;37(2):196-203. http:// dx.doi.org/10.1038/aps.2015.88

22. Macotela Y, Emanuelli B, Bång AM, Espinoza DO, Boucher J, Beebe K, et al. Dietary leucine - An environmental modifier of insulin resistance acting on multiple levels of metabolism. PLoS One. 2011;6(6):e21187. http://dx.doi.org/10.1371/journal.pone.0021187

23. El-Bassossy HM, El-Fawal R, Fahmy A, Watson ML. Arginase inhibition alleviates hypertension in the metabolic syndrome. Br J Pharmacol. 2013;169(3):693-703. http://dx.doi.org/10.1111/bph.12144

24. Polis B, Srikanth K, Gurevich V, Gil-Henn H, Samson A. L-Norvaline, a new therapeutic agent against Alzheimer's disease. Neural Regen Res. 2019;14(9):1562-72. http://dx.doi.org/10.4103/ 1673-5374.255980

25. Muche A, Arendt T, Schliebs R. Oxidative stress affects processing of amyloid precursor protein in vascular endothelial cells. PLoS One. 2017;12(6):e0178127. http://dx.doi.org/10.1371/journal. pone. 0178127

26. Melov S, Adlard PA, Morten K, Johnson F, Golden TR, Hinerfeld D, et al. Mitochondrial oxidative stress causes hyperphosphorylation of tau. PLoS One. 2007;2(6):e536. http://dx.doi.org/10.1371/ journal.pone.0000536

27. Smith MA, Casadesus G, Joseph JA, Perry G. Amyloid- $\beta$ and $\tau$ serve antioxidant functions in the aging and Alzheimer brain. Free Radic Biol Med. 2002;33(9):1194-9. http://dx.doi.org/10.1016/ S0891-5849(02)01021-3

28. Nunomura A, Tamaoki T, Tanaka K, Motohashi N, Nakamura M, Hayashi T, et al. Intraneuronal amyloid $\beta$ accumulation and oxidative damage to nucleic acids in Alzheimer disease. Neurobiol Dis. 2010;37(3):731-7. http://dx.doi.org/10.1016/j.nbd.2009.12.012

29. Castellani RJ, Lee HG, Siedlak SL, Nunomura A, Hayashi T, Nakamura M, et al. Reexamining Alzheimer's disease: Evidence for a protective role for amyloid- $\beta$ protein precursor and amyloid- $\beta$. J Alzheimers Dis. 2009;18(2):447-52. http://dx.doi.org/10.3233/JAD-2009-1151

30. Motter R, Vigo-Pelfrey C, Kholodenko D, Barbour R, Johnson-Wood K, Galasko D, et al. Reduction of $\beta$-amyloid peptide 42 in the cerebrospinal fluid of patients with Alzheimer's disease. Ann Neurol. 1995;38(4):643-8. http://dx.doi.org/10.1002/ana.410380413

31. Haapalinna F, Paajanen T, Penttinen J, Kokki H, Kokki M, Koivisto AM, et al. Low cerebrospinal fluid amyloid-beta concentration is associated with poorer delayed memory recall in women. Dement Geriatr Cogn Dis Extra. 2016;6(2):303-12. http://dx.doi.org/10.1159/000446425

32. Guerreiro R, Bras J. The age factor in Alzheimer's disease. Genome Med. 2015;7:106. http://dx.doi. org/10.1186/s13073-015-0232-5

33. Zhu X, Tan L, Wang H, Jiang T, Cao L, Wang C, et al. Rate of early onset Alzheimer's disease: A systematic review and meta-analysis. Ann Transl Med. 2015;3(3):38.

34. Campion D, Dumanchin C, Hannequin D, Dubois B, Belliard S, Puel M, et al. Early-onset autosomal dominant Alzheimer disease: Prevalence, genetic heterogeneity, and mutation spectrum. Am J Hum Genet. 1999;65(3):664-70. http://dx.doi.org/10.1086/302553

35. Smith M. Genetics of Alzheimer's disease. In: Dementia. 5th ed. David Ames, John T. O'Brien, Alistair Burns. Editors. Boca Raton, FL: CRC Press, Taylor \& Francis Group; 2017;519-528.

36. Finckh U, Kuschel C, Anagnostouli M, Patsouris E, Pantes GV, Gatzonis S, et al. Novel mutations and repeated findings of mutations in familial Alzheimer disease. Neurogenetics. 2005;6(2):85-9. http:// dx.doi.org/10.1007/s10048-005-0211-x 
37. Barber RC. The genetics of Alzheimer's disease. Scientifica (Cairo). 2012;2012:246210. http://dx.doi. org/10.6064/2012/246210

38. Smits LL, Pijnenburg YAL, Koedam ELGE, Van Der Vlies AE, Reuling IEW, Koene T, et al. Early onset alzheimer's disease is associated with a distinct neuropsychological profile. J Alzheimer's Dis. 2012;30(1):101-8. http://dx.doi.org/10.3233/JAD-2012-111934

39. Joubert S, Gour N, Guedj E, Didic M, Guériot C, Koric L, et al. Early-onset and late-onset Alzheimer's disease are associated with distinct patterns of memory impairment. Cortex. 2016;74:217-32. http:// dx.doi.org/10.1016/j.cortex.2015.10.014

40. Chiaravalloti A, Koch G, Toniolo S, Belli L, Di Lorenzo F, Gaudenzi S, et al. Comparison between early-onset and late-onset Alzheimer's disease patients with amnestic presentation: CSF and 18F-FDG PET study. Dement Geriatr Cogn Dis Extra. 2016;6(1):108-19. http://dx.doi.org/10.1159/000441776

41. Prohovnik I, Perl DP, Davis KL, Libow L, Lesser G, Haroutunian V. Dissociation of neuropathology from severity of dementia in late-onset Alzheimer disease. Neurology. 2006;66(1):49-55. http:// dx.doi.org/10.1212/01.wnl.0000191298.68045.50

42. Dorothée G, Bottlaender M, Moukari E, De Souza LC, Maroy R, Corlier F, et al. Distinct patterns of antiamyloid- $\beta$ antibodies in typical and atypical Alzheimer disease. Arch Neurol. 2012;69(9):1181-5. http://dx.doi.org/10.1001/archneurol.2012.604

43. Panegyres PK, Chen H-Y. Differences between early and late onset Alzheimer's disease. Am J Neurodegener Dis. 2013;2(4):300-6.

44. Poblador-Plou B, Calderón-Larrañaga A, Marta-Moreno J, Hancco-Saavedra J, Sicras-Mainar A, Soljak M, et al. Comorbidity of dementia: A cross-sectional study of primary care older patients. BMC Psychiatry. 2014;14:84. http://dx.doi.org/10.1186/1471-244X-14-84

45. Albert D. Dorland's illustrated medical dictionary. 32nd ed. Saunders; 2011.

46. De La Monte SM, Tong M. Brain metabolic dysfunction at the core of Alzheimer's disease. Biochem Pharmacol. 2014;88(4):548-59. http://dx.doi.org/10.1016/j.bcp.2013.12.012

47. Pagani M, Nobili F, Morbelli S, Arnaldi D, Giuliani A, Öberg J, et al. Early identification of MCI converting to AD: A FDG PET study. Eur J Nucl Med Mol Imaging. 2017;44(12):2042-52. http://dx.doi. org/10.1007/s00259-017-3761-x

48. Inoue K, Tsutsui H, Akatsu H, Hashizume Y, Matsukawa N, Yamamoto T, et al. Metabolic profiling of Alzheimer's disease brains. Sci Rep. 2013;3:2364. http://dx.doi.org/10.1038/srep02364

49. Salek RM, Xia J, Innes A, Sweatman BC, Adalbert R, Randle S, et al. A metabolomic study of the CRND8 transgenic mouse model of Alzheimer's disease. Neurochem Int. 2010;56(8):937-47. http:// dx.doi.org/10.1016/j.neuint.2010.04.001

50. Paglia G, Stocchero M, Cacciatore S, Lai S, Angel P, Alam MT, et al. Unbiased metabolomic investigation of Alzheimer's disease brain points to dysregulation of mitochondrial aspartate metabolism. J Proteome Res. 2016;15(2):608-18. http://dx.doi.org/10.1021/acs.jproteome.5b01020

51. Graham SF, Chevallier OP, Elliott CT, Hölscher C, Johnston J, Mcguinness B, et al. Untargeted metabolomic analysis of human plasma indicates differentially affected polyamine and L-arginine metabolism in mild cognitive impairment subjects converting to Alzheimer's disease. PLoS One. 2015;10(3):1-16. http://dx.doi.org/10.1371/journal.pone.0119452

52. González-Domínguez R, García-Barrera T, Vitorica J, Gómez-Ariza JL. Metabolomic investigation of systemic manifestations associated with Alzheimer's disease in the APP/PS1 transgenic mouse model. Mol Biosyst. 2015;11(9):2429-40. http://dx.doi.org/10.1039/C4MB00747F

53. Pan X, Nasaruddin MB, Elliott CT, McGuinness B, Passmore AP, Kehoe PG, et al. Alzheimer's diseaselike pathology has transient effects on the brain and blood metabolome. Neurobiol Aging. 2016; 38:151-63. http://dx.doi.org/10.1016/j.neurobiolaging.2015.11.014

54. Maarouf CL, Walker JE, Sue LI, Dugger BN, Beach TG, Serrano GE. Impaired hepatic amyloid-beta degradation in Alzheimer's disease. PLoS One. 2018;13(9):e0203659. http://dx.doi.org/10.1371/journal.pone. 0203659

55. Mittal K, Mani RJ, Katare DP. Type 3 diabetes: Cross talk between differentially regulated proteins of type 2 diabetes mellitus and Alzheimer's disease. Sci Rep. 2016;6:25589. http://dx.doi.org/10.1038/ srep25589 
56. Kandimalla R, Thirumala V, Reddy PH. Is Alzheimer's disease a type 3 diabetes? A critical appraisal. Biochim Biophys Acta Mol Basis Dis. 2017 May;1863(5):1078-89. http://dx.doi.org/10.1016/j. bbadis.2016.08.018

57. De La Monte SM, Wands JR. Alzheimer's disease is type 3 diabetes-evidence reviewed. J Diabetes Sci Technol. 2008;2(6):1101-13. http://dx.doi.org/10.1177/193229680800200619

58. Ahtiluoto S, Polvikoski T, Peltonen M, Solomon A, Tuomilehto J, Winblad B, et al. Diabetes, Alzheimer disease, and vascular dementia: A population-based neuropathologic study. Neurology. 2010;75(13):1195-202. http://dx.doi.org/10.1212/WNL.0b013e3181f4d7f8

59. Alford S, Patel D, Perakakis N, Mantzoros CS. Obesity as a risk factor for Alzheimer's disease: Weighing the evidence. Obesity Rev. 2018;19(2):269-80. http://dx.doi.org/10.1111/obr.12629

60. Craft S, Baker LD, Montine TJ, Minoshima S, Watson GS, Claxton A, et al. Intranasal insulin therapy for Alzheimer disease and amnestic mild cognitive impairment: A pilot clinical trial. Arch Neurol. 2012;69(1):29-38. http://dx.doi.org/10.1001/archneurol.2011.233

61. Wang J, Gallagher D, Devito LM, Cancino GI, Tsui D, He L, et al. Metformin activates an atypical PKC-CBP pathway to promote neurogenesis and enhance spatial memory formation. Cell Stem Cell. 2012;11(1):23-35. http://dx.doi.org/10.1016/j.stem.2012.03.016

62. Asadbegi M, Yaghmaei P, Salehi I, Ebrahim-Habibi A, Komaki A. Neuroprotective effects of metformin against $\mathrm{A} \beta$-mediated inhibition of long-term potentiation in rats fed a high-fat diet. Brain Res Bull. 2016;121:178-85. http://dx.doi.org/10.1016/j.brainresbull.2016.02.005

63. Campbell JM, Stephenson MD, De Courten B, Chapman I, Bellman SM, Aromataris E. Metformin use associated with reduced risk of dementia in patients with diabetes: A systematic review and meta-analysis. J Alzheimer's Dis. 2018;65(4):1225-36. http://dx.doi.org/10.3233/JAD-180263

64. Koenig AM, Mechanic-Hamilton D, Xie SX, Combs MF, Cappola AR, Xie L, et al. Effects of the insulin sensitizer metformin in Alzheimer disease: Pilot data from a randomized placebo-controlled crossover study. Alzheimer Dis Assoc Disord. 2017;31(2):107-13. http://dx.doi.org/10.1097/ WAD.0000000000000202

65. Gad ES, Zaitone SA, Moustafa YM. Pioglitazone and exenatide enhance cognition and downregulate hippocampal beta amyloid oligomer and microglia expression in insulin-resistant rats. Can J Physiol Pharmacol. 2016;94(8):819-28. http://dx.doi.org/10.1139/cjpp-2015-0242

66. Galimberti D, Scarpini E. Pioglitazone for the treatment of Alzheimer's disease. Expert Opin Investig Drugs. 2017;26(1):97-101. http://dx.doi.org/10.1080/13543784.2017.1265504

67. Zhao Y, Zhao B. Natural antioxidants in prevention and management of Alzheimer's disease. Front Biosci Elit. 2012;4:794-808. http://dx.doi.org/10.2741/e419

68. Ruhe RC, McDonald RB. Use of antioxidant nutrients in the prevention and treatment of type 2 diabetes. J Am Coll Nutr. 2001 Oct;20(5 Suppl):363S-9S; discussion 381S-3S. http://dx.doi.org/10. 1080/07315724.2001.10719169

69. Huang HC, Zheng BW, Guo Y, Zhao J, Zhao JY, Ma XW, et al. Antioxidative and neuroprotective effects of curcumin in an Alzheimer's disease rat model co-treated with intracerebroventricular streptozotocin and subcutaneous D-galactose. J Alzheimers Dis. 2016;52(3):899-911. http://dx.doi.org/10.3233/JAD-150872

70. Tang M, Taghibiglou C, Liu J. The mechanisms of action of curcumin in Alzheimers disease. J Alzheimers Dis. 2017;58(4):1003-16. http://dx.doi.org/10.3233/JAD-170188

71. Roehr S, Pabst A, Luck T, Riedel-heller SG. Is dementia incidence declining in high-income countries? A systematic review and meta-analysis. Clin Epidemiol. 2018;10:1233-47. http://dx.doi.org/10.2147/ CLEP.S163649

72. Langa KM. Is the risk of Alzheimer's disease and dementia declining? Alzheimers Res Ther. 2015;7(1):34. http://dx.doi.org/10.1186/s13195-015-0118-1

73. Langa KM, Larson EB, Crimmins EM, Faul JD, Levine DA, Kabeto MU, et al. A comparison of the prevalence of dementia in the United States in 2000 and 2012. JAMA Intern Med. 2017;2800(1):51-8. http://dx.doi.org/10.1001/jamainternmed.2016.6807

74. Matthews FE, Arthur A, Barnes LE, Bond J, Jagger C, Robinson L, et al. A two-decade comparison of prevalence of dementia in individuals aged 65 years and older from three geographical areas of 
England: Results of the cognitive function and ageing study I and II. Lancet. 2013;382(9902):1405-12. http://dx.doi.org/10.1016/S0140-6736(13)61570-6

75. Shetty PK, Galeffi F, Turner DA. Cellular links between neuronal activity and energy homeostasis. Front Pharmacol. 2012;3:43. http://dx.doi.org/10.3389/fphar.2012.00043

76. Finkel T, Holbrook NJ. Oxidants, oxidative stress and the biology of ageing. Nature. 2000;408(6809):239-47. http://dx.doi.org/10.1038/35041687

77. Chen X, Guo C, Kong J. Oxidative stress in neurodegenerative diseases. Neural Regen Res. 2012;7(5):376-85.

78. Mclellan ME, Kajdasz ST, Hyman BT, Bacskai BJ. In vivo imaging of reactive oxygen species specifically associated with thioflavine s-positive amyloid plaques by multiphoton microscopy. J Neurosci. 2003;23(6):2212-17. http://dx.doi.org/10.1523/JNEUROSCI.23-06-02212.2003

79. Perry G, Taddeo MA, Nunomura A, Zhu X, Zenteno-Savin T, Drew KL, et al. Comparative biology and pathology of oxidative stress in Alzheimer and other neurodegenerative diseases: Beyond damage and response. Comp Biochem Physiol C Toxicol Pharmacol. 2002;133(4):507-13. http://dx.doi. org/10.1016/S1532-0456(02)00119-9

80. Maritim AC, Sanders RA, Watkins JB. Diabetes, oxidative stress, and antioxidants: A review. J Biochem Mol Toxicol. 2003;17(1):24-38. http://dx.doi.org/10.1002/jbt.10058

81. Rahimi R, Nikfar S, Larijani B, Abdollahi M. A review on the role of antioxidants in the management of diabetes and its complications. Biomed Pharmacother. 2005;59(7):365-73. http://dx.doi. org/10.1016/j.biopha.2005.07.002

82. Ahmad A, Sattar MZA, Rathore HA, Hussain AI, Khan SA, Fatima T, et al. Antioxidant activity and free radical scavenging capacity of L-arginine and NaHS: A comparative in vitro study. Acta Pol Pharm Drug Res. 2015;72(2):245-52.

83. Hosseini M, Anaeigoudari A, Beheshti F, Soukhtanloo M, Nosratabadi R. Protective effect against brain tissues oxidative damage as a possible mechanism for beneficial effects of L-arginine on lipopolysaccharide induced memory impairment in rats. Drug Chem Toxicol. 2018;4l(2):175-81. http://dx.doi. org/10.1080/01480545.2017.1336173

84. Wallner S, Hermetter A, Mayer B, Wascher TC. The alpha-amino group of L-arginine mediates its antioxidant effect. Eur J Clin Invest. 2001;31(2):98-102. http://dx.doi. org/10.1046/j.1365-2362.2001.00771.x

85. Milyutina N. Antiradical and antioxidant effect of arginine and its action on lipid peroxidation in hypoxia. Bull Exp Biol Med. 1990;110(9):263-5. http://dx.doi.org/10.1007/BF00840280

86. Wu G, Jaeger LA, Bazer FW, Rhoads JM. Arginine deficiency in preterm infants: Biochemical mechanisms and nutritional implications. J Nutr Biochem. 2004;15(8):442-51. http://dx.doi.org/10.1016/j. jnutbio.2003.11.010

87. Hristina K, Langerholc T, Trapecar M. Novel metabolic roles of L-arginine in body energy metabolism and possible clinical applications. J Nutr Health Aging. 2014;18(2):213-18. http://dx.doi. org/10.1007/s12603-014-0015-5

88. Bergin D, Jing Y, Mockett B, Zhang H, Abraham W, Liu P. Altered plasma arginine metabolome precedes behavioural and brain arginine metabolomic profile changes in the APPswe/PS1 $\Delta \mathrm{E} 9$ mouse model of Alzheimer's disease. Transl Psychiatry. 2018;18(2):213-18. http://dx.doi.org/10.1038/ s41398-018-0149-z

89. Vemula P, Jing Y, Zhang H, Hunt JB, Sandusky-Beltran LA, Lee DC, et al. Altered brain arginine metabolism in a mouse model of tauopathy. Amino Acids. 2019;51(3):513-28. http://dx.doi.org/10.1007/ s00726-018-02687-X

90. Liu P, Fleete MS, Jing Y, Collie ND, Curtis MA, Waldvogel HJ, et al. Altered arginine metabolism in Alzheimer's disease brains. Neurobiol Aging. 2014;35(9):1992-2003. http://dx.doi.org/10.1016/j. neurobiolaging.2014.03.013

91. Gueli MC, Taibi G. Alzheimer's disease: Amino acid levels and brain metabolic status. Neurol Sci. 2013;34(9):1575-9. http://dx.doi.org/10.1007/s10072-013-1289-9 
92. Ibanez C, Simo C, Martin-Alvarez PJ, Kivipelto M, Winblad B, Cedazo-Minguez A, et al. Toward a predictive model of Alzheimer's disease progression using capillary electrophoresis-mass spectrometry metabolomics. Anal Chem. 2012;84(20):8532-40. http://dx.doi.org/10.1021/ac301243k

93. Fonteh AN, Harrington RJ, Tsai A, Liao P, Harrington MG. Free amino acid and dipeptide changes in the body fluids from Alzheimer's disease subjects. Amino Acids. 2007;32(2):213-24. http://dx.doi. org/10.1007/s00726-006-0409-8

94. Zhang Y, Tang Y, Dammer E, Liu J, Zhao Y, Zhu L, et al. Dysregulated urinary arginine metabolism in older adults with amnestic mild cognitive impairment. Front Aging Neurosci. 2019;11:90. http:// dx.doi.org/10.3389/fnagi.2019.00090

95. Liu P, Jing Y, Collie ND, Campbell SA, Zhang H. Pre-aggregated A $325-35$ alters arginine metabolism in the rat hippocampus and prefrontal cortex. Neuroscience. 2011;193:269-82. http://dx.doi. org/10.1016/j.neuroscience.2011.07.054

96. Bergin DH, Jing Y, Zhang H, Liu P. A single intracerebroventricular A $325-35$ infusion leads to prolonged alterations in arginine metabolism in the rat hippocampus and prefrontal cortex. Neuroscience. 2015;298:367-79. http://dx.doi.org/10.1016/j.neuroscience.2015.04.034

97. Fonar G, Polis B, Maltsev A, Samson AO. Intracerebroventricular administration of L-arginine improves spatial memory acquisition in triple transgenic mice via reduction of oxidative stress and apoptosis. Transl Neurosci. 2018;9:43-53. http://dx.doi.org/10.1515/tnsci-2018-0009

98. Ohtsuka Y, Nakaya J. Effect of oral administration of L-arginine on senile dementia. Am J Med. 2000;108(5):439. http://dx.doi.org/10.1016/S0002-9343(99)00396-4

99. Koga Y, Akita Y, Nishioka J, Yatsuga S, Povalko N, Tanabe Y, et al. L-arginine improves the symptoms of strokelike episodes in MELAS. Neurology. 2005;64(4):710-12. http://dx.doi.org/10.1212/01. WNL.0000151976.60624.01

100. Hatzoglou M, Fernandez J, Yaman I, Closs E. Regulation of cationic amino acid transport: The story of the CAT-1 transporter. Annu Rev Nutr. 2004;24:377-99. http://dx.doi.org/10.1146/annurev. nutr.23.011702.073120

101. O’Kane RL, Viña JR, Simpson I, Zaragozá R, Mokashi A, Hawkins RA. Cationic amino acid transport across the blood-brain barrier is mediated exclusively by system y+. Am J Physiol Endocrinol Metab. 2006;291(2):E412-19. http://dx.doi.org/10.1152/ajpendo.00007.2006

102. Tachikawa M, Hosoya K. Transport characteristics of guanidino compounds at the blood-brain barrier and blood-cerebrospinal fluid barrier: Relevance to neural disorders. Fluids Barriers CNS. 2011;8(1):13. http://dx.doi.org/10.1186/2045-8118-8-13

103. Stoll J, Wadhwani KC, Smith QR. Identification of the cationic amino acid transporter (system y+) of the rat blood-brain barrier. J Neurochem. 1993;60(5):1956-9. http://dx.doi.org/10.1111/j.1471-4159.1993. tb13428.x

104. Shin WW, Fong WF, Pang SF, Wong PC. Limited blood brain barrier transport of polyamines. J Neurochem. 1985;44(4):1056-9. http://dx.doi.org/10.1111/j.1471-4159.1985.tb08724.x

105. Badaut J, Copin JC, Fukuda AM, Gasche Y, Schaller K, da Silva RF. Increase of arginase activity in old apolipoprotein-E deficient mice under Western diet associated with changes in neurovascular unit. J Neuroinflammation. 2012;9:132. http://dx.doi.org/10.1186/1742-2094-9-132

106. Nelson DL, Cox MM. Lehninger principles of biochemistry. 3rd ed. New York: Wort Publishers; 2004.

107. Balez R, Ooi L. Getting to NO Alzheimer's disease: Neuroprotection versus neurotoxicity mediated by nitric oxide. Oxid Med Cell Longev. 2016;2016:3806157. http://dx.doi.org/10.1155/2016/3806157

108. Wink DA, Hanbauer I, Krishna MC, DeGraff W, Gamson J, Mitchell JB. Nitric oxide protects against cellular damage and cytotoxicity from reactive oxygen species. Proc Natl Acad Sci USA. 1993;90(21):9813-17. http://dx.doi.org/10.1073/pnas.90.21.9813

109. Durante W, Johnson FK, Johnson RA. Arginase: A critical regulator of nitric oxide synthesis and vascular function. Clin Exp Pharmacol Physiol. 2007;34(9):906-11. http://dx.doi. org/10.1111/j.1440-1681.2007.04638.x

110. Ditlevsen DK, Køhler LB, Berezin V, Bock E. Cyclic guanosine monophosphate signalling pathway plays a role in neural cell adhesion molecule-mediated neurite outgrowth and survival. J Neurosci Res. 2007;85(4):703-11. http://dx.doi.org/10.1002/jnr.21175

111. Förstermann U, Xia N, Li H. Roles of vascular oxidative stress and nitric oxide in the pathogenesis of atherosclerosis. Circ Res. 2017;120(4):713-35. http://dx.doi.org/10.1161/CIRCRESAHA.116.309326 
112. Li H, Förstermann U. Uncoupling of endothelial NO synthase in atherosclerosis and vascular disease. Curr Opin Pharmacol. 2013;13(2):161-7. http://dx.doi.org/10.1016/j.coph.2013.01.006

113. Chang CI, Liao JC, Kuo L. Arginase modulates nitric oxide production in activated macrophages. Am J Physiol. 1998;274(1):H342-8. http://dx.doi.org/10.1152/ajpheart.1998.274.1.H342

114. Ryoo S, Bhunia A, Chang F, Shoukas A, Berkowitz DE, Romer LH. OxLDL-dependent activation of arginase II is dependent on the LOX-1 receptor and downstream RhoA signaling. Atherosclerosis. 2011;214(2):279-87. http://dx.doi.org/10.1016/j.atherosclerosis.2010.10.044

115. Lange PS, Langley B, Lu P, Ratan RR. Novel roles for arginase in cell survival, regeneration, and translation in the central nervous system. J Nutr. 2004;134(10 Suppl):2812S-17S; discussion 2818S-19S. http://dx.doi.org/10.1093/jn/134.10.2812S

116. Pandey D, Bhunia A, Oh YJ, Chang F, Bergman Y, Kim JH, et al. OxLDL triggers retrograde translocation of arginase2 in aortic endothelial cells via ROCK and mitochondrial processing peptidase. Circ Res. 2014;115(4):450-9. http://dx.doi.org/10.1161/CIRCRESAHA.115.304262

117. Polis B, Kolluru DS, Elliott E, Gil-Henn H, Samson AO. L-norvaline reverses cognitive decline and synaptic loss in a murine model of Alzheimer's disease. Neurotherapeutics. 2018;15(4):1036-54. http://dx.doi.org/10.1007/s13311-018-0669-5

118. Hansmannel F, Sillaire A, Kamboh MI, Lendon C, Pasquier F, Hannequin D, et al. Is the urea cycle involved in Alzheimer's disease? J Alzheimer's Dis. 2010;21(3):1013-21. http://dx.doi.org/10.3233/ JAD-2010-100630

119. Narayanan SP, Xu Z, Putluri N, Sreekumar A, Lemtalsi T, Caldwell RW, et al. Arginase 2 deficiency reduces hyperoxia-mediated retinal neurodegeneration through the regulation of polyamine metabolism. Cell Death Dis. 2014;5(2):e1075. http://dx.doi.org/10.1038/cddis.2014.23

120. Pernet V, Bourgeois P, Di Polo A. A role for polyamines in retinal ganglion cell excitotoxic death. J Neurochem. 2007;103(4):1481-90. http://dx.doi.org/10.1111/j.1471-4159.2007.04843.x

121. Xiong Y, Yepuri G, Montani JP, Ming XF, Yang Z. Arginase-II deficiency extends lifespan in mice. Front Physiol. 2017;8:682. http://dx.doi.org/10.3389/fphys.2017.00682

122. Rognstad R. Sources of ammonia for urea synthesis in isolated rat liver cells. BBA Gen Subj. 1977;496(2):249-54. http://dx.doi.org/10.1016/0304-4165(77)90306-3

123. Saheki T, Sato Y, Takada S, Katsunuma T. Regulation of urea synthesis in rat liver. J Biochem. 1979;86(3):745-50. http://dx.doi.org/10.1093/oxfordjournals.jbchem.a132579

124. Bode AM, Foster JD, Nordlieon RC. Glycogenesis from glucose and ureagenesis in isolated perfused rat livers. Biochemistry. 1994 Mar;269(11):7879-86.

125. Bensemain F, Hot D, Ferreira S, Dumont J, Bombois S, Maurage C, et al. Evidence for induction of the ornithine transcarbamylase expression in Alzheimer's disease. Mol Psychiatry. 2009;14(1):106-16. http://dx.doi.org/10.1038/sj.mp.4002089

126. Hansmannel F, Lendon C, Pasquier F, Dumont J, Hannequin D, Chapuis J, et al. Is the ornithine transcarbamylase gene a genetic determinant of Alzheimer's disease? Neurosci Lett. 2009;449(1):76-80. http://dx.doi.org/10.1016/j.neulet.2008.10.081

127. Li C, Salditt T. Structure of magainin and alamethicin in model membranes studied by $\mathrm{x}$-ray reflectivity. Biophys J. 2006;91(9):3285-300. http://dx.doi.org/10.1529/biophysj.106.090118

128. Brosnan JT, Brosnan ME. Branched-chain amino acids: Enzyme and substrate regulation. J Nutr. 2006;91(9):3285-300.

129. Hall TR, Wallin R, Reinhart GD, Hutson SM. Branched chain aminotransferase isoenzymes. Purification and characterization of the rat brain isoenzyme. J Biol Chem. 1993;268(5):3092-8.

130. Bixel MG, Hutson SM, Hamprecht B. Cellular distribution of branched-chain amino acid aminotransferase isoenzymes among rat brain glial cells in culture. J Histochem Cytochem. 1997;45(5):685-94. http://dx.doi.org/10.1177/002215549704500506

131. Bixel MG, Shimomura Y, Hutson SM, Hamprecht B. Distribution of key enzymes of branchedchain amino acid metabolism in glial and neuronal cells in culture. J Histochem Cytochem. 2001;49(3):407-18. http://dx. doi.org/10.1177/002215540104900314

132. Fernstrom J. Branched-chain amino acids and brain function. J Nutr. 2005;135(6 Suppl):1539S-46S. http://dx.doi.org/10.1093/jn/135.6.1539S

133. Meldrum BS. Glutamate as a neurotransmitter in the brain: Review of physiology and pathology. J Nutr. 2000;130(4S Suppl):1007S-15S. http://dx.doi.org/10.1093/jn/130.4.1007S 
134. Hawkins RA. The blood-brain barrier and glutamate. Am J Clin Nutr. 2009;90(3):867S-74S. http:// dx.doi.org/10.3945/ajcn.2009.27462BB

135. Price MT, Olney JW, Lowry OH, Buchsbaum S. Uptake of exogenous glutamate and aspartate by circumventricular organs but not other regions of brain. J Neurochem. 1981;36(5):1774-80. http:// dx.doi.org/10.1111/j.1471-4159.1981.tb00430.x

136. González-Domínguez R, García-Barrera T, Gómez-Ariza JL. Metabolite profiling for the identification of altered metabolic pathways in Alzheimer's disease. J Pharm Biomed Anal. 2015;107:75-81. http:// dx.doi.org/10.1016/j.jpba.2014.10.010

137. Toledo JB, Arnold M, Kastenmüller G, Chang R, Baillie RA, Han X, et al. Metabolic network failures in Alzheimer's disease: A biochemical road map. Alzheimers Dement. 2017;13(9):965-984. http:// dx.doi.org/10.1016/j.jalz.2017.01.020

138. Morris GP, Clark IA, Vissel B. Inconsistencies and controversies surrounding the amyloid hypothesis of Alzheimer's disease. Acta Neuropathol Commun. 2014;2(1):135. http://dx.doi.org/10.1186/ s40478-014-0135-5

139. Makin S. The amyloid hypothesis on trial. Nature. 2018;559(7715):S4-S7. http://dx.doi.org/10.1038/ d41586-018-05719-4

140. Canter RG, Penney J, Tsai LH. The road to restoring neural circuits for the treatment of Alzheimer's disease. Nature. 2016;539(7628):187-96. http://dx.doi.org/10.1038/nature20412

141. Godyń J, Jończyk J, Panek D, Malawska B. Therapeutic strategies for Alzheimer's disease in clinical trials. Pharmacol Rep. 2016;68(1):127-38. http://dx.doi.org/10.1016/j.pharep.2015.07.006 